\title{
Scaling relation for high-temperature biodiesel surrogate ignition delay times
}

\author{
Matthew F. Campbell ${ }^{\mathrm{a}, *}$, David F. Davidson ${ }^{\mathrm{b}}$, Ronald K. Hanson ${ }^{\mathrm{b}}$ \\ ${ }^{a}$ Combustion Research Facility, Sandia National Laboratory, Livermore, CA 94550, USA \\ ${ }^{b}$ Department of Mechanical Engineering, Stanford University, Stanford, CA 94405, USA
}

\begin{abstract}
High-temperature Arrhenius ignition delay time correlations are useful for revealing the underlying parameter dependencies of combustion models, for simplifying and optimizing combustion mechanisms for use in engine simulations, for scaling experimental data to new conditions for comparison purposes, and for guiding in experimental design. We have developed a scaling relationship for Fatty Acid Methyl Ester (FAME) ignition time data taken at high temperatures in $4 \% \mathrm{O}_{2} / \mathrm{Ar}$ mixtures behind reflected shocks using an aerosol shock tube:

$$
\tau_{\text {ign }}[\mathrm{ms}]=2.24 \times 10^{-6}[\mathrm{~ms}](P[\mathrm{~atm}])^{-0.41}(\phi)^{0.30}\left(C_{n}\right)^{-0.61} \exp \left(\frac{37.1[\mathrm{kcal} / \mathrm{mol}]}{\hat{R}_{u}[\mathrm{kcal} / \mathrm{mol}-\mathrm{K}] T[\mathrm{~K}]}\right)
$$

Additionally, we have combined our ignition delay time data for methyl decanoate, methyl palmitate, methyl oleate, and methyl linoleate with other experimental results in the literature in order to derive fuel-specific oxygen-mole-fraction scaling parameters for these surrogates. In this article, we discuss the significance of the parameter values, compare our correlation to others found in the literature for different classes of fuels, and contrast the above expression's performance with correlations obtained using leading FAME kinetic models in $4 \% \mathrm{O}_{2} / \mathrm{Ar}$ mixtures.
\end{abstract}

Keywords: Shock tube, Ignition delay time, Fatty Acid Methyl Ester (FAME), Biodiesel surrogate, Correlation

PACS: $88.85 . \mathrm{mb}, 82.33 . \mathrm{Vx}$

*Corresponding author; Tel.: +1-925-294-2530; Fax: +1-925-294-2276

Email address: mf campbe sandia.gov (Matthew F. Campbell)

URL: http://crf.sandia.gov/ (Matthew F. Campbell), http://hanson. stanford.edu/ (David F. Davidson) 


\section{Introduction}

Increasingly stringent regulations for heavy-duty diesel engine exhaust have led manufacturers to search for methods of reducing nitrogen oxide $\left(\mathrm{NO}_{\mathrm{x}}\right)$ and particulate matter $(\mathrm{PM})$ emissions [1-3]. Such techniques include Exhaust Gas Recirculation (EGR), in which a portion of the exhaust gases are combined with the pre-combustion fuel/air blend in order to decrease the oxygen content of the mixture and hence reduce $\mathrm{NO}_{\mathrm{x}}[4,5]$, and blending fossil diesel fuel with small fractions of biodiesel fuel, which can reduce PM [6-10]. However, these prevention techniques are complicated by the fact that EGR sometimes results in increased exhaust PM [4, 5], and in some engines biodiesel has been linked with increased levels of tailpipe $\mathrm{NO}_{\mathrm{x}}$ [6-12]. Thus, care must be taken in using EGR and biodiesel in conjunction [13]. This motivates a thorough understanding of biodiesel combustion in lower-oxygen-content $(\leq 21 \%)$ mixtures.

Shock tube ignition delay times are a critical component for developing and validating combustion models [14-17]. These models are used to evaluate fuel blends and design diesel engines [18-26]. High-temperature shock tube ignition delay time data can be summarized by correlations that serve to reveal the underlying dependence of ignition times on important parameters such as pressure or equivalence ratio [27]. Such correlations are useful for simplifying/optimizing combustion models for use in diesel engine Computational Fluid Dynamics (CFD) simulations, for scaling experimental data to new conditions for comparison purposes, and for guiding in experimental design [28-32]. Several authors have suggested high-temperature 
Arrhenius-like correlations for various fuels (normal alkanes, oxygenates, etc.), including those

40 listed in References [27, 33-46] (see also Table 1). Other more complex ignition delay time correlations have also been suggested that cover both high and low temperatures [47, 49]. However, we are unaware of any such correlation for large biodiesel surrogates at high temperatures and low oxygen concentrations; this provides motivation for the present work.

[Table 1 about here.]

\section{Previous biodiesel ignition studies}

Recently, our research group published two articles containing high-temperature ignition delay times measured in $1 \%, 4 \%$, and $21 \%$ oxygen/argon mixtures behind reflected shock waves in an aerosol shock tube for a series of biodiesel surrogate molecules in the Fatty Acid Methyl Ester (FAME) family [50, 51]. These fuels included methyl decanoate (MD, $\mathrm{C}_{11} \mathrm{H}_{22} \mathrm{O}_{2}$; see Figso ure 11, which was measured at $1 \%$ and $21 \%$ oxygen mole fractions, and methyl laurate (MLA, $\mathrm{C}_{13} \mathrm{H}_{26} \mathrm{O}_{2}$ ), methyl myristate (MM, $\mathrm{C}_{15} \mathrm{H}_{30} \mathrm{O}_{2}$ ), methyl palmitate (MP, $\mathrm{C}_{17} \mathrm{H}_{34} \mathrm{O}_{2}$ ), methyl oleate ( $\mathrm{MO}, \mathrm{C}_{19} \mathrm{H}_{36} \mathrm{O}_{2}$ ), and methyl linoleate ( $\mathrm{ML}, \mathrm{C}_{19} \mathrm{H}_{34} \mathrm{O}_{2}$ ), which were measured in $4 \%$ oxygen mixtures. Importantly, the fact that these shock tube studies were performed at oxygen concentrations at or below $21 \%$ allows these experiments to serve as a proxy for EGR behavior. Our

55 first goal in this work was to use these two data sets to develop an ignition delay time correlation for large FAMEs in $4 \% \mathrm{O}_{2} / \mathrm{Ar}$ mixtures that captures the effects of temperature $T$, pressure $P$, equivalence ratio $\phi$, molecular size (carbon chain length) $C_{n}$, and, if necessary, hydrogen unsaturation (number of $\mathrm{C}=\mathrm{C}$ double bonds) $U_{d}$. Moreover, our second ambition was to synthesize other FAME ignition delay data available in the literature [45, 46, 52, 60] in order to develop scaling parameters for the dependence of ignition time on the mixture oxygen mole fraction $x_{\mathrm{O}_{2}}$.

[Figure 1 about here.]

[Table 2 about here.]

Before proceeding, we wish to note that other shock tube studies have specifically simulated 65 EGR conditions by adding $\mathrm{CO}_{2} / \mathrm{H}_{2} \mathrm{O} / \mathrm{O}_{2} / \mathrm{N}_{2}$ blends to the pre-shock mixture [48, 55, 61]. However, these works do not include experimentation at oxygen concentrations as low as used in our 
studies [50, 51]. Also, it should be mentioned that many shock tube studies are performed with fuel/oxygen mixtures that are diluted in argon rather than in nitrogen [29]. The effects of the choice of diluent are well-understood and thus will not be considered here [62].

\section{Experimental methods}

Complete experimental details for our previous biodiesel studies can be found in References [50, 51, 63]; therefore, only a brief overview will be given here. All ignition delay shocktests were conducted using the Stanford University Aerosol Shock Tube (AST). Experimental conditions are summarized in Table 2.

The AST uses a series of gate valves and pressure differentials to deliver a spatially uniform aerosol of micron-sized fuel droplets suspended in a carrier gas consisting of oxygen, argon, and fuel vapor into the last meter of the shock tube driven section. An incident shock wave, generated via strain-induced rupture of a diaphragm by high-pressure helium in the driver section, passes through the aerosol, causing the droplets to evaporate and diffuse into the carrier gas; this creates a uniform premixed combustion environment. When the incident shock wave reaches the endwall of the tube, it reflects and passes through the premixed gas, compressing and heating it to the temperature and pressure of the combustion experiment, known as $T_{5}$ and $P_{5}$, respectively.

A helium-neon laser passing through the shock tube at a distance of approximately $3 \mathrm{~cm}$ from the endwall is used to measure the equivalence ratio of the mixture (see also References [64, 65]).

85 Ignition delay times are marked by the emission from kinetically excited $\mathrm{OH}$ radicals $\left(\mathrm{OH}^{*}\right)$ at $306 \pm 75 \mathrm{~nm}$, also at an endwall distance of $3 \mathrm{~cm}$. Uncertainties in ignition times are typically $\pm 30 \%$, conservatively estimated by considering individual error contributions from temperature $( \pm 1 \%)$, pressure $( \pm 2 \%)$, and equivalence ratio $( \pm 7 \%)[63$.

\section{Analysis}

\section{4.1. Ignition delay correlation}

For our analysis we chose to use the ignition delay time $\tau_{i g n}$ correlation of Davidson et al. [42]:

$$
\tau_{i g n}=A P^{a} \phi^{b} C_{n}^{c} \exp \left(\frac{\hat{E}_{A}}{\hat{R}_{u} T}\right)
$$


In this expression, input values are temperature $T[\mathrm{~K}]$, pressure $P[\mathrm{~atm}]$, equivalence ratio $\phi$, and molecular size (carbon chain length) $C_{n}$. Fitting parameters include $a / b / c$ (the fitting exponents), the A-factor $A[\mathrm{~ms}]$, and the activation energy $\hat{E}_{A}[\mathrm{kcal} / \mathrm{mol}] ; \hat{R}_{u}=1.987 \times 10^{-3}[\mathrm{kcal} / \mathrm{mol}-$ $\mathrm{K}]$ [66, 67] is the ideal gas constant. Among the available correlations found in the literature (see several in Table 1), Equation 1] is advantageous because its input values are directly measured/controlled experimental parameters and also its form is similar to Arrhenius reaction rate constant expressions [27, 29]. The importance of fuel hydrogen saturation (number of $\mathrm{C}=\mathrm{C}$ double bonds) will be discussed in Section 4.2 .

We fit Equation 1 to our $x_{\mathrm{O}_{2}}=0.04$ ignition delay time data for MLA, MM, MP, MO, and ML while accounting for experimental uncertainties in $T, P$, and $\phi$. This was made possible using Igor Pro software combined with the ODRPACK95 algorithm for Orthogonal Distance Regression (ODR) [68-70]. Fuel impurities and uncertainties in mixture composition were small and thus not considered. Fitting coefficients derived using this method are presented in Table 3 together with standard errors ( \pm values).

[Table 3 about here.]

While ODR can account for errors in fitting inputs, it is not able to provide a value for the coefficient of multiple determination $\left(R^{2}\right)$ or supply $p$-values for indicating the importance of the fitting parameters. Thus, we used the R statistics program with the MASS package [71, 72] to analyze the logarithm of Equation 1 .

$$
\ln \left(\tau_{i g n}\right)=\ln (A)+a \ln (P)+b \ln (\phi)+c \ln \left(C_{n}\right)+\frac{\hat{E}_{A}}{\hat{R}_{u}}\left(\frac{1}{T}\right)
$$

using linear regression. The analysis revealed a large coefficient of multiple determination $\left(R^{2}=\right.$ 0.941), an indication of a high goodness-of-fit. Moreover, it showed (99.9\% confidence level) that the probabilities that the values of $A, a, b, c$, and $\hat{E}_{A}$ were derived by chance alone (i.e., that these values were actually are equal to zero) were $p<1 \times 10^{-11}$ for all parameters, indicating that these were appropriately included in the model. (Values for the fitting parameters $a, b, c$, and $\hat{E}_{A}$, derived using linear regression, are within $10 \%$ of those obtained using ODR; the difference is attributable to the specified uncertainties in the $T, P$, and $\phi$ inputs, as well as differences between the fitting algorithms. Hence, we believe these fitting statistics to be relevant here.) Finally, we note that ignition delay time data can be scaled from one condition $\left(\tau_{\text {ign }}^{\text {unscaled }}, P^{\text {unscaled }}, \phi^{\text {unscaled }}\right.$, 
$\left.C_{n}^{\text {unscaled }}, T\right)$ to another $\left(\tau_{i g n}^{\text {scaled }}, P^{\text {common }}, \phi^{\text {common }}, C_{n}^{\text {common }}, T\right)$ according to Equation 2 .

$$
\tau_{\text {ign }}^{\text {scaled }}=\tau_{\text {ign }}^{\text {unscaled }}\left(\frac{P^{\text {common }}}{P^{\text {unscaled }}}\right)^{a}\left(\frac{\phi^{\text {common }}}{\phi^{\text {unscaled }}}\right)^{b}\left(\frac{C_{n}^{\text {common }}}{C_{n}^{\text {unscaled }}}\right)^{c}
$$

\subsection{Alternate correlations}

We also experimented with a correlation that included a term for the degree of hydrogen unsaturation $U_{d}$. This parameter can be thought of as the number of $\mathrm{C}=\mathrm{C}$ double bonds in the alkane-like carbon chain, where a fully saturated molecule has $U_{d}=0$, and $U_{d}=2$ corresponds to two degrees of unsaturation (i.e., two double bonds in the carbon chain). This was incorporated by multiplying Equation 1 by the factor $\left(U_{d}+1\right)^{d}$, where the exponent $d$ was a fitting exponent parameter:

$$
\tau_{i g n}=A P^{a} \phi^{b} C_{n}^{c}\left(U_{d}+1\right)^{d} \exp \left(\frac{\hat{E}_{A}}{\hat{R}_{u} T}\right)
$$

The addition of unity to $U_{d}$ was performed so that fully saturated molecules $\left(U_{d}=0\right)$ could be included in the linear regression. (A unity linear shift such as this has been recommended for use in logarithmic transformations [73, 74].) The logarithm of Equation 3 was analyzed using linear regression, revealing a $p$-value for the parameter $d$ of $p=0.105$. This indicates that for our data set this parameter was not significant even at the $90 \%$ level. By way of further confirmation, we applied the Akaike Information Criterion (AIC) with a likelihood-ratio test, with the result that the likelihood of information loss from a model that included $U_{d}$ was not significantly lower than the likelihood of information loss from a model that did not include $U_{d}$ [75]. Thus, we concluded that including fuel unsaturation was not necessary to capture the observed trends in the ignition data. Importantly, this seems to indicate that under the conditions studied, unsaturation has little effect on ignition delay times for large methyl esters.

Furthermore, it should be noted that the correlation introduced above assumes that the pressure, equivalence ratio, carbon number, and unsaturation scaling are not functions of temperature. In reality, the data show that at certain temperatures, the ignition delay time values for the FAMEs studied are insensitive to these parameters, or even that the scaling may reverse (negative instead of positive, etc.) [50, 51]. A third fitting equation that allowed parameters $a, b$, and $c$ to vary as linear functions of temperature was also developed. The resulting correlation did not significantly improve the fitting results, and moreover was not warranted, given the uncertainty in the experimental data. Thus, while in principle a temperature-dependent scaling should be employed to summarize these data, such a regression has not been proposed here. 


\subsection{Oxygen mole fraction scaling}

As mentioned earlier, several other studies have examined high-temperature ignition delay times of FAMES. In particular, Haylett, Davidson, and Hanson (2012) measured MD ignition times in $21 \% \mathrm{O}_{2} / \mathrm{Ar}$ mixtures [45], Li et al. (2012) and Wang and Oehlschlaeger (2012) measured MD ignition times in $21 \% \mathrm{O}_{2} / \mathrm{N}_{2}$ mixtures [55, 56], and Wang, Gowdagiri, and Oehlschlaeger (2014) measured ignition times of MP, MO, and ML in $21 \% \mathrm{O}_{2} / \mathrm{N}_{2}$ mixtures [58]. We have combined these data sets with our own ignition delay time results in order to derive oxygen mole fraction scaling parameters $g$ for MD, MP, MO, and ML according to Equation 4

$$
\tau_{\text {ign }}^{\text {scaled }}=\tau_{\text {ign }}^{\text {unscaled }}\left(\frac{x_{\mathrm{O}_{2}}^{\text {common }}}{x_{\mathrm{O}_{2}}^{\text {unsaled }}}\right)^{g}
$$

In order to obtain these parameters, we first scaled the data sets to common pressure and equivalence ratio values using published or conventional scaling values [51, 56, 58], then secondly fit the data using the logarithm-based approach outlined above (similar to Equation 1 . The resulting oxygen mole fraction scaling parameters $g$ are provided in Table 4 . Note that these parameters are dependent on the pressure and equivalence ratio scaling exponents $(a$ and $b)$ used in the first step of this analysis, but in general a $10 \%$ change in these exponents $(a$ or $b)$ results in a change in the oxygen mole fraction scaling exponent $g$ of $10 \%$ or less.

[Table 4 about here.]

\section{Discussion}

\subsection{Graphical demonstration}

The results of scaling the ignition delay times are best displayed graphically. Figure 2 shows the raw (unscaled) ignition delay times for MLA, MM, MP, MO, and ML, while Figure 3 shows the data scaled to $P^{\text {common }}=6 \mathrm{~atm}, \phi^{\text {common }}=1$, and $C_{n}^{\text {common }}=16$ according to Equation 2 using the exponents given in Table 3. Notice that the correlation appropriately collapses the data to a general trend line, and that the error bars in the data points generally overlap this line. Both the graphical depiction and the statistical tests applied above serve to indicate the appropriateness of the equation and fitting parameters chosen. The residual range in the data points seen in the scaled plot (Figure 3) is due in part to the uncertainty in the original data and also in part to the temperature-dependent nature of the scaling parameters, as discussed in Section 4.2 
[Figure 2 about here.]

[Figure 3 about here.]

As seen in Figures 2 and 3 the different FAMEs examined in this study have very similar ignition times; unscaled ignition delay times for different fuels differ by only about a factor of 2-3 at any given temperature. The similarity in high-temperature ignition times for FAMEs has been observed by others as well [58, 76-78], and has also been seen for other classes of hydrocarbons [79, 80].

\subsection{Experimental comparison}

The parameters $a, b, c$, and $\hat{E}_{A}$ from Equation 1 , and $g$ from Equation 4 have important physical significance and allow for quantitative comparisons of different fuels. Table 5 offers a profile of different experimentally-determined scaling values for several classes of fuels, together with those determined in this work. Several observations can be made based on this table.

[Table 5 about here.]

\subsubsection{Pressure}

In all cases shown in Table 5, the pressure scaling exponent $a$ is negative. This reflects the fact that collision rates increase with increasing pressure, thus decreasing the time necessary to generate the critical radical concentration needed for an explosion. A similar pressure scaling can be inferred using the Lindemann et al. mechanism for unimolecular decomposition reactions, as pointed out by Imbert et al. [30, 81]. Returning to the pressure scaling values in Table 5], it is important to note that not all fuels exhibit the commonly accepted $\tau \propto P^{-1}$ (i.e., $a=-1$ ) scaling. Use of this scaling is generally applicable, but in some cases can lead to significantly inaccurate results.

\subsubsection{Equivalence ratio}

Table 5 also shows that the equivalence ratio-dependence of hydrocarbon ignition times varies with oxygen concentration. At high $x_{\mathrm{O}_{2}}$, the scaling parameter $b$ is negative, whereas at low $x_{\mathrm{O}_{2}}, b$ is positive. This change is found in some kinetic mechanisms as well. One such mechanism is the Mehl et al. $n$-heptane model, which is a well-established tool for simulating the combustion of this primary reference fuel and diesel surrogate [82, 83]. Figure 4 shows the 
simulated equivalence ratio scaling exponent $b$ at several oxygen mole fractions and four temperatures; notice, for instance, that at $1200 \mathrm{~K}$, for $x_{\mathrm{O}_{2}}>0.2$ the model yields $b<0$, whereas the opposite is true for lower oxygen mole fractions. We conducted an analysis to examine the sensitivity of the $\mathrm{OH}$ radical concentration $[\mathrm{OH}]$, a strong indicator of ignition at high temperatures, to the reaction rates of this $n$-heptane model. The modeling revealed that (at $1200 \mathrm{~K}$ and $7 \mathrm{~atm}$ ) as $x_{\mathrm{O}_{2}}$ increased, the reactions

$$
\mathrm{H}_{2} \mathrm{O}_{2}+\mathrm{M} \longrightarrow 2 \mathrm{OH}+\mathrm{M}
$$

and

$$
\mathrm{C}_{7} \mathrm{H}_{16}+\mathrm{HO}_{2} \longrightarrow \mathrm{C}_{7} \mathrm{H}_{15}+\mathrm{H}_{2} \mathrm{O}_{2}
$$

became significant ignition promoters, while the reaction

$$
\mathrm{H}_{2} \mathrm{O}_{2}+\mathrm{O}_{2} \longrightarrow 2 \mathrm{HO}_{2}
$$

began to inhibit ignition. The precise coupling between the individual reaction rates and the equivalence ratio scaling is beyond the scope of this work. Nevertheless, the experimentally and computationally observed changes in the equivalence ratio scaling exponent $b$ with $x_{\mathrm{O}_{2}}$ could have important implications for EGR in diesel engines, and thus should be studied further. Based on the above discussion, we note, in agreement with Horning et al. (2002), that scaling ignition times over a large range of equivalence ratios is not advisable [27].

[Figure 4 about here.]

\subsubsection{Carbon chain length}

The carbon chain length scaling exponent $c$ is seen to be negative in all cases, indicating that at high temperatures, ignition times tend to decrease as molecular size increases. Also, a relatively close match is seen between the value measured by Horning, Davidson, and Hanson [27] ( $c=-0.50)$ and that of this study $(c=-0.61)$. As pointed out by Davidson et al. [42], the increase in fuel reactivity with carbon chain length can be related to the decrease in average $\mathrm{C}-\mathrm{H}$ bond strength (bond dissociation energy) with increasing carbon chain length. In particular, longer carbon chains have higher ratios of weaker secondary $\mathrm{C}-\mathrm{H}$ bonds $\left(\mathrm{C}-\mathrm{C}_{2} \mathrm{H}_{2}\right)$ to stronger primary $\mathrm{C}-\mathrm{H}$ bonds $\left(\mathrm{C}-\mathrm{CH}_{3}\right)$ [84-86]. Overall, however, it should be noted that differences between ignition times of large alkane-like fuels at high temperatures are expected to be relatively small [56, 79, 80]. 


\subsection{Activation energy}

Values for the activation energy $\hat{E}_{A}$ for the hydrocarbons listed in Table 5 range from about

25 to $51 \mathrm{kcal} / \mathrm{mol}$, with most values near $45 \mathrm{kcal} / \mathrm{mol}$. This parameter gives an indication of the sensitivity of the fuel's reactivity to temperature. It can can also provide insight into the temperature-dependence of the unimolecular fuel decomposition pathways, as these have a large influence on high-temperature ignition times [50]. A larger activation energy indicates an increased sensitivity of the fuel's reactivity to temperature.

Close examination of the values in Table 5 seems to indicate a correlation between the oxygen mole fraction and the activation energy; in general, activation energy values seem to be greater than $40 \mathrm{kcal} / \mathrm{mol}$ for oxygen concentrations less than about $5 \%$, and less than $30 \mathrm{kcal} / \mathrm{mol}$ for $21 \%$ oxygen mixtures. We employed the Mehl et al. $n$-heptane mechanism [82, 83] to examine this insight further at three pressures for stoichiometric argon-diluted mixtures, and the results are depicted in Figure 5 For all pressures shown, at oxygen contents greater than 21\%, the activation energy is relatively insensitive to oxygen content. However, for oxygen contents less than $21 \%$, the activation energy increases as the oxygen mole fraction decreases, and the effect is more pronounced at lower pressures as well. Importantly, this implies that high-temperature fuel ignition in diesel engines operating under oxygen-deprived EGR conditions is more temperaturesensitive, indicating that engine control may be more difficult.

\section{[Figure 5 about here.]}

Finally, we also note that the dependence of activation energy on oxygen content has implications for uncertainty quantification in shock tube ignition delay time measurements. Ignition time uncertanties are often derived from experimental temperature uncertanties using a simple Arrhenius equation:

$$
\begin{gathered}
\tau_{i g n}=A \exp \left(\frac{\hat{E}_{A}}{\hat{R}_{u} T}\right) \\
\frac{\Delta \tau_{i g n}}{\tau_{i g n}}=\left(\frac{-E_{A}}{\hat{R}_{u} T}\right)\left(\frac{\Delta T}{T}\right)
\end{gathered}
$$

Here, $\frac{\Delta \tau_{i g n}}{\tau_{i g n}}$ is the uncertainty in ignition time and $\frac{\Delta T}{T}$ is the uncertainty in the experimental temperature. Equation 6 implies that, all other factors held constant, ignition times measured in lower oxygen content mixtures may inherently have higher uncertainty because of the increased 
activation energy values observed under these conditions. It should be noted, however, that working with dilute mixtures provides other benefits, such as minimal heat release and less violent detonation events.

\subsection{Oxygen mole fraction}

The values for the oxygen mole fraction scaling exponent $g$ for MD, MP, MO, and ML are fairly similar to each other and to the values for $n$-alkanes obtained by Horning et al. (2002) [27] and by Haylett et al. (2012) [45]. This points to the similarity of high-temperature ignition processes between FAMEs and normal alkanes. Also, like the pressure scaling exponents, all oxygen mole fraction scaling exponents are negative. This reflects the fact that increased reactant concentrations lead to higher collision rates, thereby promoting ignition.

\subsection{Unsaturation}

While this analysis did not reveal a significant hydrogen unsaturation $U_{d}$ scaling exponent ( $d$; see Section 4.2] for the FAMEs studied, the data for MO and ML alone [50] may indicate that this parameter nevertheless has some importance. In general, a positive unsaturation scaling $(d>0)$ is predicted (increasing unsaturation leads to longer ignition times), which may be explained by the fact that the double $\mathrm{C}=\mathrm{C}$ bond in unsaturated FAMEs changes the bond strength of the neighboring $\mathrm{C}-\mathrm{H}$ and $\mathrm{C}-\mathrm{C}$ bonds [85, 87].

\subsection{Graphical comparison}

A graphical comparison of several ignition time correlations found in the literature with that specified in this article is provided in Figure 6. These correlation trend lines were computed at $P=4 \mathrm{~atm}, \phi=1, C_{n}=8$, and $x_{\mathrm{O}_{2}}=0.04$. The correlations for $n$-alkanes [27, 42] predict similar ignition times to those for the FAMEs studied here, which is understandable given that unimolecular decomposition of the alkane-like chain in FAMEs governs biodiesel ignition times at high temperatures [50]. Also, the trend line for $i$-octane correctly shows that it has much longer ignition times than the $n$-alkanes and FAMEs. Lastly, the activation energy (slope) of the FAME trend line is lower than that of the other fuels shown (see also Table 5p; this could be caused in part by the temperature-dependent scaling that is characteristic of FAMEs but less common among $n$-alkanes [50, 51, 56].

[Figure 6 about here.] 


\subsection{Modeling comparison} from chemical kinetic models [27, 30]. This can provide a quick benchmark for the accuracy of a model because the mechanism-derived scaling correlation parameter values are determined from numerous simulated conditions rather than just one set. In this work, we obtained ignition correlations from the Herbinet et al. (2011) [76], Westbrook et al. [50, 77, 78], and value.

[Figure 7 about here.]

[Table 6 about here.]

From Figure 7 , it can be seen that the Herbinet model generally over-predicts FAME ignition times. Also, from Table 6 it appears that this model has an activation energy closer to most $n$ alkanes (see values listed in Table 5) rather than the FAMEs studied by Campbell et al. [50, 51]. Additionally, the Herbinet correlation shows a positive $C_{n}$ scaling $(c>0)$, reflecting observations by Campbell et al. [51] that this model does not capture the effect of carbon chain length at present. In contrast, the Westbrook et al. [50, 77, 78] model, although not including a carbon number scaling parameter $(c=0)$, seems to produce a correlation that more closely approximates that obtained from the experimental data. Finally, the Saggese et al. [88-90] biodiesel model also closely matches the experimental data correlation, but with a more accurate activation energy 


\section{Summary}

We have examined the FAME ignition delay time data of Campbell et al. [50, 51] in order to determine a correlation that captures the pressure, equivalence ratio, and carbon chain length scaling of biodiesel surrogate ignition at low-oxygen-concentration conditions. The resulting correlation revealed negative pressure scaling, positive equivalence ratio scaling, and a negative carbon chain length dependence. Moreover, we have combined our experimental results with that of others [45, 55, 56, 58] in order to derive oxygen mole fraction scaling parameters for methyl decanoate, methyl palmitate, methyl oleate, and methyl linoleate, revealing negative scaling that is similar to that of normal alkanes. We have also provided comparisons of our correlation parameters to those derived for other classes of fuels, finding similar scaling parameters to those of $n$-alkanes but somewhat lower activation energy values. Finally, we obtained ignition correlations using the Herbinet et al. [76], Westbrook et al. [50, 77, 78], and Saggese et al. [88-90] biodiesel models, finding that the Herbinet model generally over-predicted ignition times and that the Westbrook and Saggese models had better accuracy. We believe that the correlations obtained in this work will be useful in developing EGR techniques for modern diesel engines, and will also aid in experimental designs for new biodiesel surrogate studies.

\section{Acknowledgments}

The measurement of ignition delay times of biodiesel surrogates was based upon work supported by, or in part by, the U.S. Army Research Laboratory and the U.S. Army Research Office under contract/grant number W911NF1310206. M.F.C. is supported by the Division of Chemical Sciences, Geosciences, and Biosciences, the Office of Basic Energy Sciences (BES), the U.S. Department of Energy (DOE). Also, during a portion of this work, M.F.C. was supported by a National Defense Science and Engineering Graduate (NDSEG) Fellowship, 32 CFR 168a. Sandia

National Laboratories is a multi-program laboratory managed and operated by Sandia Corporation, a wholly owned subsidiary of Lockheed Martin Corporation, for the U.S. Department of Energy's National Nuclear Security Administration under contract DE-AC04-94AL85000. The authors would like to thank Kristen J. Campbell for useful insights and discussions concerning the statistical analysis.

[1] EPA. Paving the way toward cleaner, more efficient trucks. Technical Report EPA-420-F-11-032, United States Environmental Protection Agency, Office of Transportation and Air Quality, August, 2011. 
[2] R. LaHood and L. P. Jackson. Greenhouse gas emissions standards and fuel efficiency standards for medium- and heavy-duty engines and vehicles; Final rule. Federal Register, 76(179):57106-57513, 2011.

[3] R. LaHood and B. Perciasepe. Heavy-duty engine and vehicle, and nonroad technical amendments; Final rule. Federal Register, 78(116):36370-36406, 2013.

[4] G. H. Abd-Alla. Using exhaust gas recirculation in internal combustion engines: A review. Energy Conversion and Management, 43(8):1027-1042, 2002.

[5] M. Zheng, G. T. Reader, and J. G. Hawley. Diesel engine exhaust gas recirculation - A review on advanced and novel concepts. Energy Conversion and Management, 45(6):883-900, 2004.

[6] M. S. Graboski and R. L. McCormick. Combustion of fat and vegetable oil derived fuels in diesel engines. Progress in Energy and Combustion Science, 24(2):125-164, 1998.

[7] EPA. A comprehensive analysis of biodiesel impacts on exhaust emissions. Technical Report EPA420-P-02001, United States Environmental Protection Agency, Office of Transportation and Air Quality, Assessment and Standards Division, October 2002.

310 [8] G. Knothe, C. A. Sharp, and T. W. Ryan. Exhaust emissions of biodiesel, petrodiesel, neat methyl esters, and alkanes in a new technology engine. Energy \& Fuels, 20(1):403-408, 2006.

[9] M. Lapuerta, O. Armas, and J. Rodriguez-Fernandez. Effect of biodiesel fuels on diesel engine emissions. Progress in Energy and Combustion Science, 34(2):198-223, 2008.

[10] A. Schönborn, N. Ladommatos, J. Williams, R. Allan, and J. Rogerson. The influence of molecular structure of fatty acid monoalkyl esters on diesel combustion. Combustion and Flame, 156(7):1396-1412, 2009.

[11] J. Sun, J. A. Caton, and T. J. Jacobs. Oxides of nitrogen emissions from biodiesel-fuelled diesel engines. Progress in Energy and Combustion Science, 36(6):677-695, 2010.

[12] B. M. Knight, J. A. Bittle, and T. J. Jacobs. The role of system responses on biodiesel nitric oxide emissions in a medium-duty diesel engine. International Journal of Engine Research, 12(4):336-352, 2011.

[13] K. Venkateswarlu, K.Vijaya Kumar, B. S. R. Murthy, and V. V. Subbarao. Effect of exhaust gas recirculation and ethyl hexyl nitrate additive on biodiesel fuelled diesel engine for the reduction of $\mathrm{NO}_{\mathrm{x}}$ emissions. Frontiers in Energy, 6(3):304-310, 2012.

[14] D. F. Davidson and R. K. Hanson. Recent advances in shock tube/laser diagnostic methods for improved chemical kinetics measurements. Shock Waves, 19:271-283, 2009. 10.1007/s00193-009-0203-0.

[15] M. Chaos and F. L. Dryer. Chemical-kinetic modeling of ignition delay: Considerations in interpreting shock tube data. International Journal of Chemical Kinetics, 42(3):143-150, 2010.

[16] R. K. Hanson. Applications of quantitative laser sensors to kinetics, propulsion and practical energy systems. Proceedings of the Combustion Institute, 33(1):1-40, 2011.

[17] R. K. Hanson and D. F. Davidson. Recent advances in laser absorption and shock tube methods for studies of combustion chemistry. Progress in Energy and Combustion Science, 44(0):103-114, 2014.

[18] D. A. Kouremenos, C. D. Rakopoulos, D. Hountalas, and P. Kotsiopoulos. A digital simulation of the exhaust nitric oxide and soot formation histories in the combustion chambers of a swirl chamber diesel engine. Forschung im Ingenieurwesen A, 56(1):22-32, 1990.

[19] C. K. Westbrook, J. Warnatz, and W. J. Pitz. A detailed chemical kinetic reaction mechanism for the oxidation of $i s o$-octane and $n$-heptane over an extended temperature range and its application to analysis of engine knock. 
Symposium (International) on Combustion, 22(1):893-901, 1989.

[20] C. S. Chang, Y. Zhang, K. N. C. Bray, and B. Rogg. Modelling and simulation of autoignition under simulated diesel-engine conditions. Combustion Science and Technology, 113(1):205-219, 1996.

[21] C. K. Westbrook, W. J. Pitz, and H. J. Curran. Chemical kinetic modeling study of the effects of oxygenated hydrocarbons on soot emissions from diesel engines. The Journal of Physical Chemistry A, 110(21):6912-6922, 2006. PMID: 16722706 .

[22] J. Boulanger, F. Liu, W. S. Neill, and G. J. Smallwood. An improved soot formation model for 3D Diesel engine simulations. Journal of Engineering for Gas Turbines and Power, 129(3):877-884, 2006.

[23] J. Boulanger, W. S. Neill, F. Liu, and G. J. Smallwood. An improved phenomenological soot formation submodel for three-dimensional diesel engine simulations: Extension to agglomeration of particles into clusters. Journal of Engineering for Gas Turbines and Power, 130(6):062808, Aug 2008.

[24] L. Liang, C. V. Naik, K. Puduppakkam, C. Wang, A. Modak, E. Meeks, H.-W. Ge, R. Reitz, and C. Rutland. Efficient simulation of diesel engine combustion using realistic chemical kinetics in CFD. In Society of Automotive Engineers 2010 World Congress \& Exhibition, number 2010-01-0178, Detroit, Michigan, April 13-15, 20102010. Society of Automotive Engineers.

[25] P. Jenny, D. Roekaerts, and N. Beishuizen. Modeling of turbulent dilute spray combustion. Progress in Energy and Combustion Science, 38(6):846-887, 2012.

[26] J. O'Conner and M. Musculus. Post injections for soot reduction in diesel engines: A review of current understanding. SAE International Journal of Engines, 6(1):400-421, 2013.

[27] D. C. Horning, D. F. Davidson, and R. K. Hanson. Study of the high-temperature autoignition of $n$-alkane/ $\mathrm{O}_{2} / \mathrm{Ar}$ mixtures. Journal of Propulsion and Power, 18(2):363-371, 2002.

[28] A. Lifshitz. Chapter 16.5 - Chemical and combustion kinetics: 16.5 Ignition delay times. In Gabi Ben-Dor, Ozer Igra, and Tov Elperin, editors, Handbook of Shock Waves, pages 211-VII. Academic Press, Burlington, 2001.

[29] D. F. Davidson and R. K. Hanson. Interpreting shock tube ignition data. International Journal of Chemical Kinetics, 36(9):510-523, 2004.

[30] B. Imbert, F. Lafosse, L. Catoire, C.-É. Paillard, and B. Khasainov. Formulation reproducing the ignition delays simulated by a detailed mechanism: Application to $n$-heptane combustion. Combustion and Flame, 155(3):380408, 2008.

[31] C. K. Law. Combustion Physics. Cambridge University Press, August 2010.

[32] Mohammed EL-Kasaby and Medhat A. Nemit-allah. Experimental investigations of ignition delay period and performance of a diesel engine operated with Jatropha oil biodiesel. Alexandria Engineering Journal, 52(2):141149,2013

[33] W. G. Burwell and D. R. Olson. The spontaneous ignition of isooctane air mixtures under steady flow conditions. Technical Report 650510, Society of Automotive Engineers International, 1965.

[34] A. Lifshitz, K. Scheller, A. Burcat, and G. B. Skinner. Shock-tube investigation of ignition in methane-oxygenargon mixtures. Combustion and Flame, 16(3):311-321, 1971.

[35] Alexander Burcat, Assa Lifshitz, Karl Scheller, and Gordon B. Skinner. Shock-tube investigation of ignition in propane-oxygen-argon mixtures. Symposium (International) on Combustion, 13(1):745-755, 1971. Thirteenth symposium (International) on Combustion Thirteenth symposium (International) on Combustion. 
[36] D. J. Vermeer, J. W. Meyer, and A. K. Oppenheim. Auto-ignition of hydrocarbons behind reflected shock waves. Combustion and Flame, 18(3):327-336, 1972.

[37] A. Burcat, R. F. Farmer, and R. A. Matula. Shock initiated ignition in heptane-oxygen-argon mixtures. In C. E. Treanor and J. G. Hall, editors, Shock Tubes and Waves: Proceedings of the $13^{\text {th }}$ International Symposium on Shock Tubes and Shock Waves, page 826, Niagara Falls, NY, 1982. State University of New York Press, Albany, NY.

[38] T. W. Ryan and T. J. Callahan. Engine and constant volume bomb studies of diesel ignition and combustion. Technical Report 881626, Society of Automotive Engineers International, 1988.

[39] D. F. Davidson, M. A. Oehlschlaeger, J. T. Herbon, and R. K. Hanson. Shock tube measurements of iso-octane ignition times and $\mathrm{OH}$ concentration time histories. Proceedings of the Combustion Institute, 29(1):1295-1301, 2002. Proceedings of the Combustion Institute.

[40] S. M. Daley, A. M. Berkowitz, and M. A. Oehlschlaeger. A Shock tube study of cyclopentane and cyclohexane ignition at elevated pressures. International Journal of Chemical Kinetics, 40(10):624-634, 2008.

[41] D. R. Haylett, P. P. Lappas, D. F. Davidson, and R. K. Hanson. Application of an aerosol shock tube to the measurement of diesel ignition delay times. Proceedings of the Combustion Institute, 32(1):477-484, 2009.

[42] D. F. Davidson, S. C. Ranganath, K. Y. Lam, M. Liaw, Z. Hong, and R. K. Hanson. Ignition delay time measurements of normal alkanes and simple oxygenates. Journal of Propulsion and Power, 26(2):280-287, 2010.

[43] Z. L. Zhao, Z. Chen, and S. Y. Chen. Correlations for the ignition delay times of hydrogen/air mixtures. Chinese Science Bulletin, 56(2):215-221, 2011.

[44] B. Rotavera, P. Diévart, C. Togbé, P. Dagaut, and E.L. Petersen. Oxidation kinetics of $n$-nonane: Measurements and modeling of ignition delay times and product concentrations. Proceedings of the Combustion Institute, 33(1):175$183,2011$.

[45] D. R. Haylett, D. F. Davidson, and R. K. Hanson. Ignition delay times of low-vapor-pressure fuels measured using an aerosol shock tube. Combustion and Flame, 159(2):552 - 561, 2012.

[46] B. Rotavera and E. L. Petersen. Ignition behavior of pure and blended methyl octanoate, $n$-nonane, and methylcyclohexane. Proceedings of the Combustion Institute, 34(1):435-442, 2013.

400 [47] S. Scott Goldsborough. A chemical kinetically based ignition delay correlation for iso-octane covering a wide range of conditions including the NTC region. Combustion and Flame, 156(6):1248-1262, 2009.

[48] A. Vandersickel, M. Hartmann, K. Vogel, Y. M. Wright, M. Fikri, R. Starke, C. Schulz, and K. Boulouchos. The autoignition of practical fuels at HCCI conditions: High-pressure shock tube experiments and phenomenological modeling. Fuel, 93(0):492-501, 2012.

[49] Sandeep Gowdagiri, Weijing Wang, and Matthew A. Oehlschlaeger. A shock tube ignition delay study of conventional diesel fuel and hydroprocessed renewable diesel fuel from algal oil. Fuel, 128:21-29, 2014.

[50] M. F. Campbell, D. F. Davidson, R. K. Hanson, and C. K. Westbrook. Ignition delay times of methyl oleate and methyl linoleate behind reflected shock waves. Proceedings of the Combustion Institute, 34(1):419-425, 2013.

[51] M. F. Campbell, D. F. Davidson, and R. K. Hanson. Ignition delay times of very-low-vapor-pressure biodiesel surrogates behind reflected shock waves. Fuel, 126(0):271-281, 2014.

[52] S. Garner and K. Brezinsky. Biologically derived diesel fuel and NO formation: An experimental and chemical kinetic study, Part 1. Combustion and Flame, 158(12):2289-2301, 2011.

[53] M. F. Campbell, D. F. Davidson, and R. K. Hanson. A second-generation aerosol shock tube and its use in studying 
ignition delay times of large biodiesel surrogates. In Konstantinos Kontis, editor, $28^{\text {th }}$ International Symposium on Shock Waves, pages 517-522. Springer Berlin Heidelberg, 2012.

[54] H. P. Ramirez Lancheros, M. Fikri, L. R. Cancino, G. Moréac, C. Schulz, and P. Dagaut. Autoignition of surrogate biodiesel fuel (B30) at high pressures: Experimental and modeling kinetic study. Combustion and Flame, 159(3):996-1008, 2012.

[55] Z. Li, W. Wang, Z. Huang, and M. A. Oehlschlaeger. Autoignition of methyl decanoate, a biodiesel surrogate, under high-pressure exhaust gas recirculation conditions. Energy \& Fuels, 26(8):4887-4895, 2012.

[56] W. Wang and M. A. Oehlschlaeger. A shock tube study of methyl decanoate autoignition at elevated pressures. Combustion and Flame, 159(2):476-481, 2012.

[57] W. Wang, S. Gowdagiri, and M. A. Oehlschlaeger. Comparative study of the autoignition of methyl decenoates, unsaturated biodiesel fuel surrogates. Energy \& Fuels, 27(9):5527-5532, 2013.

[58] W. Wang, S. Gowdagiri, and M. A. Oehlschlaeger. The high-temperature autoignition of biodiesels and biodiesel components. Combustion and Flame, 161(12):3014-3021, 2014

[59] V. Nguyen Hoang and L. Dinh Thi. Experimental study of the ignition delay of diesel/biodiesel blends using a shock tube. Biosystems Engineering, 134(0):1-7, 2015.

[60] Claudio Marcio Santana, Jose Eduardo Mautone Barros, Matheus Guilherme França Carvalho, and Helder Alves de Almeida, Jr. Measuring and comparing the ignition delay times of diesel, ethanol additive and biodiesel using a shock tube. Technical Report 2015-01-0802, SAE 2015 World Congress and Exhibition, 2015.

[61] B. M. Gauthier, D. F. Davidson, and R. K. Hanson. Shock tube determination of ignition delay times in full-blend and surrogate fuel mixtures. Combustion and Flame, 139(4):300-311, 2004.

[62] H.-P. S. Shen, J. Vanderover, and M. A. Oehlschlaeger. A shock tube study of iso-octane ignition at elevated pressures: The influence of diluent gases. Combustion and Flame, 155(4):739-755, 2008.

[63] M. F. Campbell. Studies of biodiesel surrogates using novel shock tube techniques. PhD thesis, Stanford University, 2014. http://purl.stanford.edu/ms343kp4994.

[64] M. F. Campbell, K. G. Freeman, D. F. Davidson, and R. K. Hanson. FTIR measurements of mid-IR absorption spectra of gaseous fatty acid methyl esters at $\mathrm{T}=25-500{ }^{\circ} \mathrm{C}$. Journal of Quantitative Spectroscopy and Radiative Transfer, 145(0):57-73, 2014.

[65] M. F. Campbell, D. R. Haylett, D. F. Davidson, and R. K. Hanson. AEROFROSH: A Shock condition calculator for multi-component-fuel aerosol-laden flows. Shock Waves, Submitted.

[66] P. J. Mohr, B. N. Taylor, and D. B. Newell. CODATA recommended values of the fundamental physical constants: 2010. Rev. Mod. Phys., 84:1527-1605, Nov 2012.

445 [67] P. J. Mohr, B. N. Taylor, and D. B. Newell. CODATA recommended values of the fundamental physical constants: 2010. Journal of Physical and Chemical Reference Data, 41(4):043109, 2012.

[68] WaveMetrics, Inc. Igor Pro Version 6.34A. Technical report, WaveMetrics, Inc., Lake Oswego, OR, USA, 2015.

[69] P. T. Boggs, R. H. Byrd, and R. B. Schnabel. A stable and efficient algorithm for nonlinear orthogonal distance regression. SIAM Journal on Scientific and Statistical Computing, 8(6):1052-1078, Nov 1987.

[70] J. W. Zwolak, P. T. Boggs, and L. T. Watson. Algorithm 869: ODRPACK95: A weighted orthogonal distance regression code with bound constraints. ACM Transactions on Mathematical Software, 33(4):27, 2007.

[71] R Core Team. R: A Language and Environment for Statistical Computing. R Foundation for Statistical Computing, 
Vienna, Austria, 2014

[72] W. N. Venables and B. D. Ripley. Modern Applied Statistics with S. Springer, New York, fourth edition, 2002. ISBN 0-387-95457-0.

[73] J. W. Osborne. Notes on the use of data transformations. Practical Assessment, Research \& Evaluation, 8(6), 2002.

[74] J. W. Osborne. Improving your data transformations: Applying the Box-Cox transformation. Practical Assessment, Research \& Evaluation, 15(12), 2010.

[75] N. P. Jewell. Statistics for Epidemiology. CRC Press LCC, Boca Raton, FL 33431, USA, 2004.

460 [76] O. Herbinet, J. Biet, M. H. Hakka, V. Warth, P.-A. Glaude, A. Nicolle, and F. Battin-Leclerc. Modeling study of the low-temperature oxidation of large methyl esters from $\mathrm{C}_{11}$ to $\mathrm{C}_{19}$. Proceedings of the Combustion Institute, 33(1):391-398, 2011.

[77] C. K. Westbrook, C. V. Naik, O. Herbinet, W. J. Pitz, M. Mehl, S. M. Sarathy, and H. J. Curran. Detailed chemical kinetic reaction mechanisms for soy and rapeseed biodiesel fuels. Combustion and Flame, 158(4):742-755, 2011. Special Issue on Kinetics.

[78] C. K. Westbrook, W. J. Pitz, S. M. Sarathy, and M. Mehl. Detailed chemical kinetic modeling of the effects of C=C double bonds on the ignition of biodiesel fuels. Proceedings of the Combustion Institute, 34(2):3049-3056, 2013.

[79] C. K. Westbrook, W. J. Pitz, H. C. Curran, J. Boercker, and E. Kunrath. Chemical kinetic modeling study of shock tube ignition of heptane isomers. International Journal of Chemical Kinetics, 33(12):868-877, 2001.

[80] C. K. Westbrook, W. J. Pitz, O. Herbinet, H. J. Curran, and E. J. Silke. A comprehensive detailed chemical kinetic reaction mechanism for combustion of $n$-alkane hydrocarbons from $n$-octane to $n$-hexadecane. Combustion and Flame, 156(1):181-199, 2009.

[81] F. A. Lindemann, S. Arrhenius, I. Langmuir, N. R. Dhar, J. Perrin, and W. C. McC. Lewis. Discussion on "the radiation theory of chemical action". Trans. Faraday Soc., 17:598-606, 1922.

[82] M. Mehl, W. J. Pitz, C. K. Westbrook, and H. J. Curran. Kinetic modeling of gasoline surrogate components and mixtures under engine conditions. Proceedings of the Combustion Institute, 33(1):193-200, 2011.

[83] M. Mehl, W. Pitz, M. Sj oberg, and J. Dec. Detailed kinetic modeling of low-temperature heat release for PRF fuels in an HCCI engine. Technical Paper 2009-01-1806, SAE International, June 152009.

[84] K. Dobek, A. Maciejewski, J. Karolczak, and W. Augustyniak. Determination of reactivities of primary, secondary, and tertiary $\mathrm{C}-\mathrm{H}$ bonds in saturated hydrocarbons from $\mathrm{S}_{2}$-xanthione fluorescence quenching. The Journal of Physical Chemistry A, 106(12):2789-2794, 2002.

[85] A. Osmont, L. Catoire, I. G okalp, and M. T. Swihart. Thermochemistry of C-C and C-H bond breaking in fatty acid methyl esters. Energy \& Fuels, 21(4):2027-2032, 2007.

[86] J. M. Hudzik, J. W. Bozzelli, and J. M. Simmie. Thermochemistry of $\mathrm{C}_{7} \mathrm{H}_{16}$ to $\mathrm{C}_{10} \mathrm{H}_{22}$ alkane isomers: Primary, secondary, and tertiary C-H bond dissociation energies and effects of branching. The Journal of Physical Chemistry A, 118(40):9364-9379, 2014.

[87] A. Osmont, L. Catoire, and P. Dagaut. Thermodynamic data for the modeling of the thermal decomposition of biodiesel. 1. Saturated and monounsaturated FAMEs. The Journal of Physical Chemistry A, 114(11):3788-3795, 2010. PMID: 19694476.

[88] C. Saggese, A. Frassoldati, A. Cuoci, T. Faravelli, and E. Ranzi. A lumped approach to the kinetic modeling of pyrolysis and combustion of biodiesel fuels. Proceedings of the Combustion Institute, 34(1):427-434, 2013. 
[89] E. Ranzi, A. Frassoldati, A. Stagni, M. Pelucchi, A. Cuoci, and T. Faravelli. Reduced kinetic schemes of complex reaction systems: Fossil and biomass-derived transportation fuels. International Journal of Chemical Kinetics, 46(9):512-542, 2014.

495 [90] A. Stagni, C. Saggese, M. Bissoli, A. Cuoci, A. Frassoldati, T. Faravelli, and E. Ranzi. Reduced kinetic model of biodiesel fuel combustion. Chemical Engineering Transactions, 37:877-882, 2014.

[91] CHEMKIN-PRO. Chemkin-pro 15131. Technical report, Reaction Design, San Diego, CA, 2013.

[92] A. Burcat, R. C. Farmer, R. L. Espinoza, and R. A. Matula. Comparative ignition delay times for selected ringstructured hydrocarbons. Combustion and Flame, 36(0):313-316, 1979. 


\section{$500 \quad$ List of Figures}

505

510

$1 \quad$ Molecular diagrams for the FAMEs examined in this work [50, 51].] . . . . . . . 21

2 Unscaled FAME data from Campbell et al. [50, 51]. Oxygen content for all data

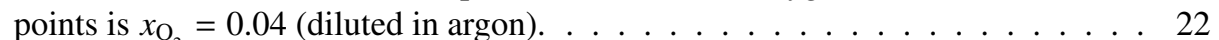

3 FAME data from Campbell et al. [50, 51] scaled to $P=6$ atm, $\phi=1$, and $C_{n}=16$ according to Equation 2 using the exponents given in Table 3 A line

showing this correlation is also provided. Oxygen content for all data points is

4 Dependence of the $\phi$-scaling exponent $b$ on oxygen mole fraction $x_{\mathrm{O}}$, as simulated for $n$-heptane ignition using the Mehl et al. mechanism [82, 83]. Diluent is

L

5 Dependence of the activation energy $E_{\mathrm{A}}$ on oxygen mole fraction $x_{\mathrm{O}_{2}}$, as simulated for $n$-heptane ignition using the Mehl et al. mechanism [82, 83$]$. Diluent is

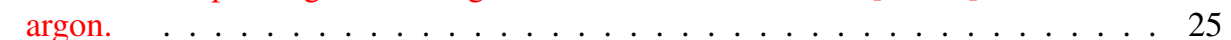

515

16 Comparison of ignition time correlations found in the literature to that obtained

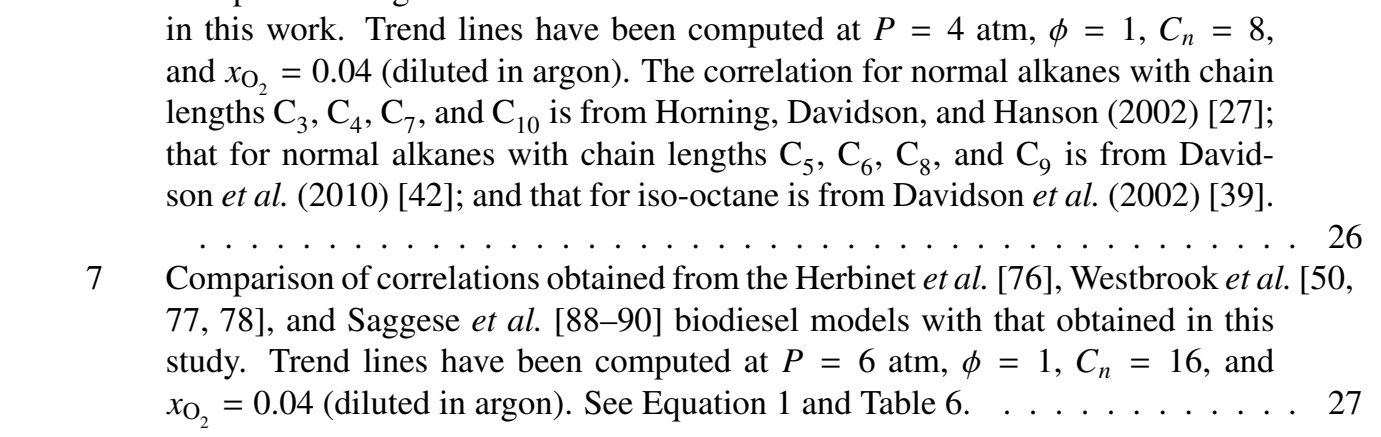




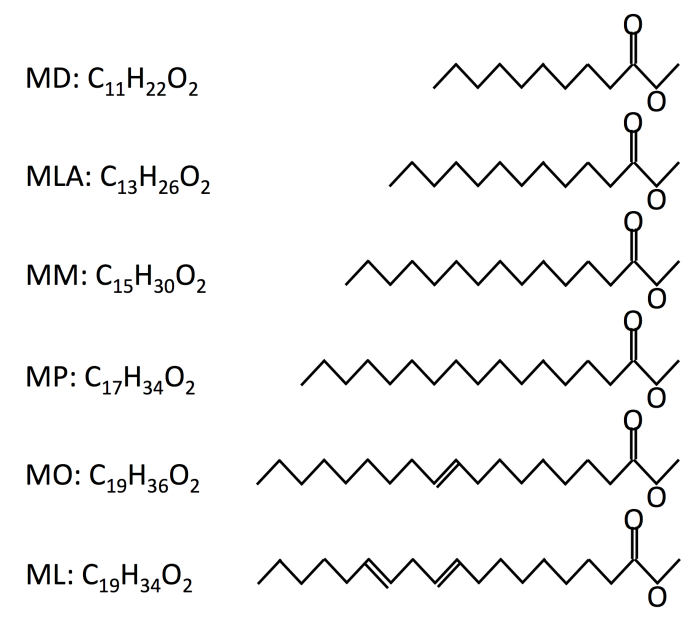

Figure 1: Molecular diagrams for the FAMEs examined in this work [50, 51]. 


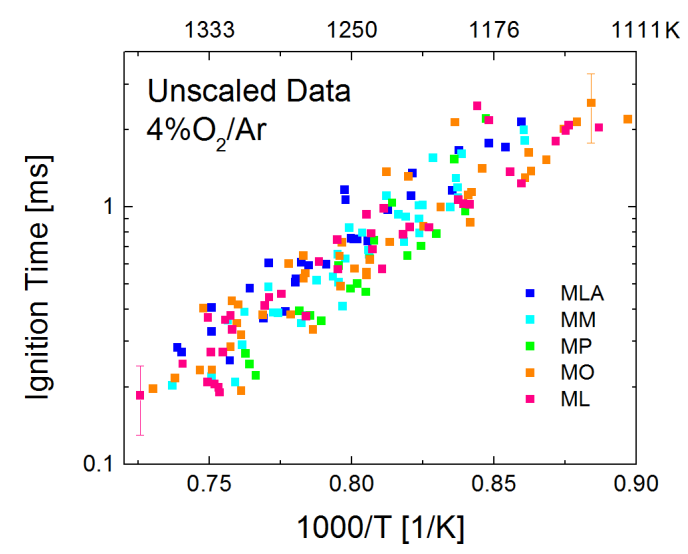

Figure 2: Unscaled FAME data from Campbell et al. [50, 51]. Oxygen content for all data points is $x_{\mathrm{O}_{2}}=0.04$ (diluted in argon). 


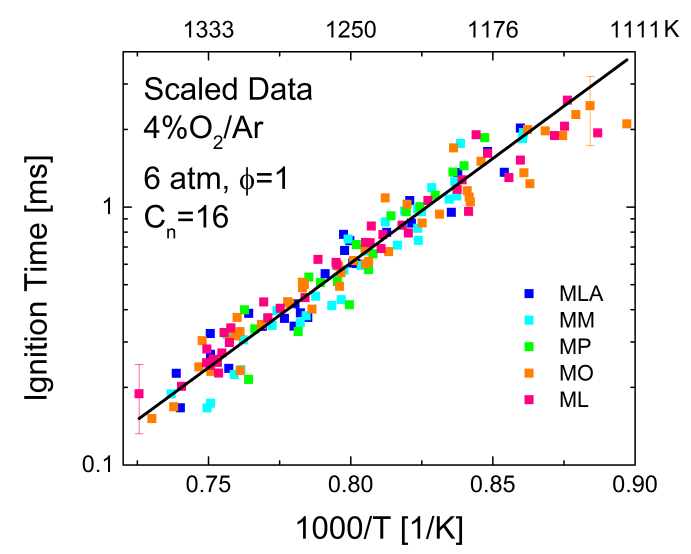

Figure 3: FAME data from Campbell et al. [50] 51] scaled to $P=6 \mathrm{~atm}, \phi=1$, and $C_{n}=16$ according to Equation2 using the exponents given in Table 3 A line showing this correlation is also provided. Oxygen content for all data points is $x_{\mathrm{O}_{2}}=0.04$ (diluted in argon). 


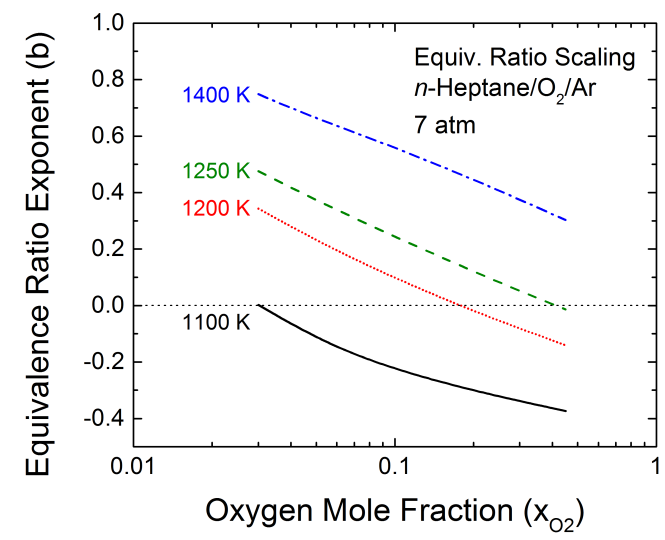

Figure 4: Dependence of the $\phi$-scaling exponent $b$ on oxygen mole fraction $x_{\mathrm{O}_{2}}$, as simulated for $n$-heptane ignition using the Mehl et al. mechanism [82, 83]. Diluent is argon. 


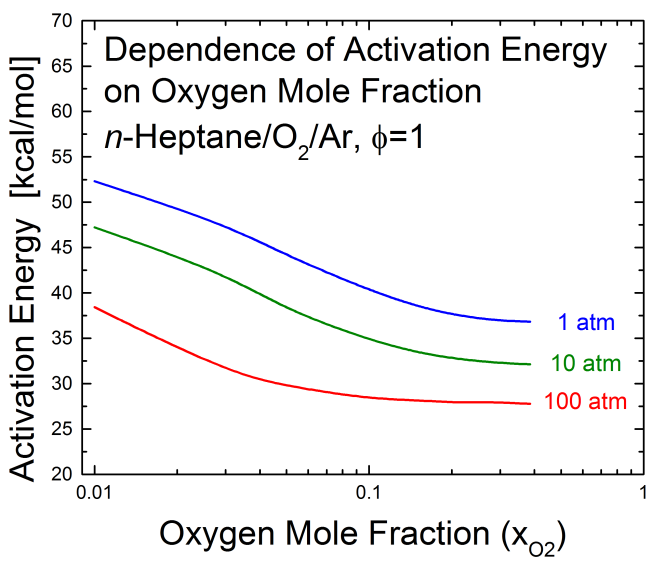

Figure 5: Dependence of the activation energy $E_{A}$ on oxygen mole fraction $x_{\mathrm{O}_{2}}$, as simulated for $n$-heptane ignition using the Mehl et al. mechanism 82, 83]. Diluent is argon. 


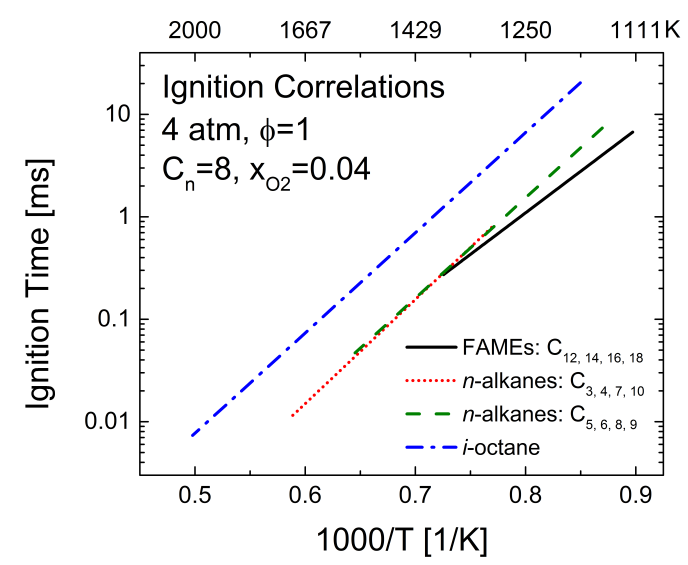

Figure 6: Comparison of ignition time correlations found in the literature to that obtained in this work. Trend lines have been computed at $P=4$ atm, $\phi=1, C_{n}=8$, and $x_{\mathrm{O}_{2}}=0.04$ (diluted in argon). The correlation for normal alkanes with chain lengths $\mathrm{C}_{3}, \mathrm{C}_{4}, \mathrm{C}_{7}$, and $\mathrm{C}_{10}$ is from Horning, Davidson, and Hanson (2002) [27]; that for normal alkanes with chain lengths $\mathrm{C}_{5}, \mathrm{C}_{6}, \mathrm{C}_{8}$, and $\mathrm{C}_{9}$ is from Davidson et al. (2010) [42]; and that for iso-octane is from Davidson et al. (2002) [39]. 


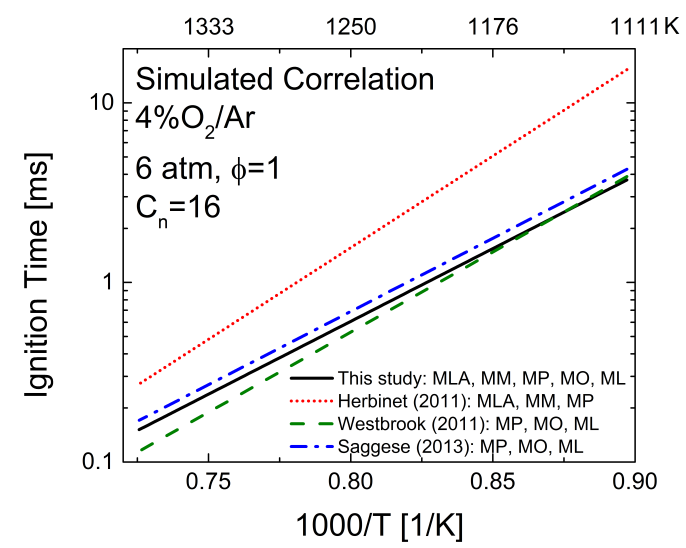

Figure 7: Comparison of correlations obtained from the Herbinet et al. [76], Westbrook et al. [50 77] 78], and Saggese et al. [88, 90] biodiesel models with that obtained in this study. Trend lines have been computed at $P=6$ atm, $\phi=1, C_{n}=16$, and $x_{\mathrm{O}_{2}}=0.04$ (diluted in argon). See Equation 1 and Table 6 


\section{List of Tables}

530

1 Select high-temperature ignition time correlations found in the literature. Con-

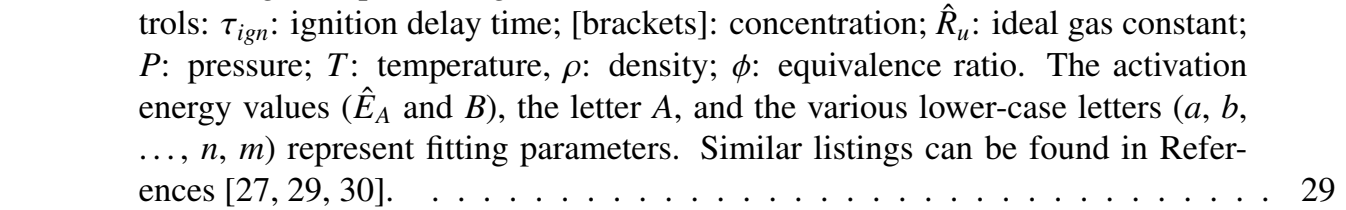

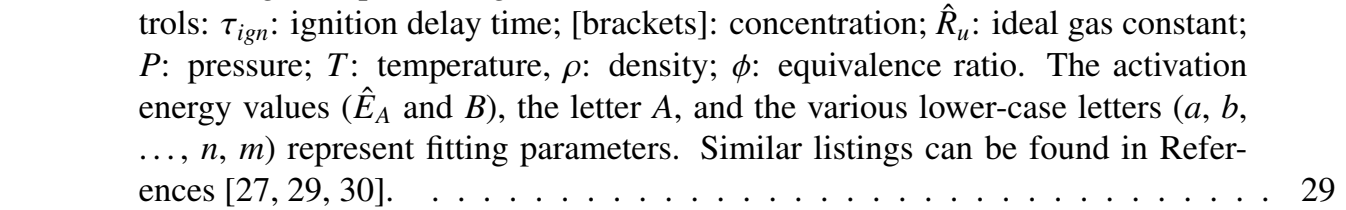

2 Experimental conditions studied in References [50, 51] for MD, MLA, MM, MP, MO, and ML. Column headings: $C_{n}$ : carbon chain length; $U_{d}$ : degree of

535 unsaturation; $T$ : temperature; $P$ : pressure; $\phi$ : equivalence ratio; $x_{\mathrm{O}_{2}}$ : oxygen

西 two studies contain 181 ignition delay time values. $\ldots \ldots \ldots$. . . . . . . 30

3 Best-fit parameters for Equation 1 based on MLA, MM, MP, MO, and ML ignition delay times at oxygen mole fraction $x_{\mathrm{O}_{2}}=0.04$ (diluted in argon; 166 data points). The \pm numbers are standard error values for the fitting parameters. $\ldots$. . . 31

540

4 Oxygen mole fraction scaling parameters $g$ for MD, MP, MO, and ML (see Equa-

tion 4). The \pm numbers are standard error values for the fitting parameters, and \begin{tabular}{|l|l|}
\hline the number of ignition delay time points used to derive each value are also given. & 32
\end{tabular}

5 Comparison of high-temperature ignition delay correlation parameters determined

545 in this study (for MD, MLA, MM, MP, MO, and ML, according to Equations 1 and 4) and parameters from the literature (see Table 1). For uncertainties in the parameters from this study, see Tables 3 and 4 A A similar table can be found in Imbert et al. [30]. . . . . . . . . . . . . . . . . . 33

6 Best-fit parameters for Equation 1 1 derived by linear regression from the Herbinet et al. [76], Westbrook et al. [50, 77, 78], and Saggese et al. [88, 90] biodiesel

550 models. The best-fit values for the Herbinet model are based only on MLA, MM, and MP because it does not include unsaturated species (e.g., MO and ML), and those for the Westbrook and Saggese models are based only on MP, MO, and ML because they do not include species smaller than MP (i.e., MM and MLA). 555 Standard error values for the fitting parameters derived in this study can be found in Table 3. Diluent is argon. 


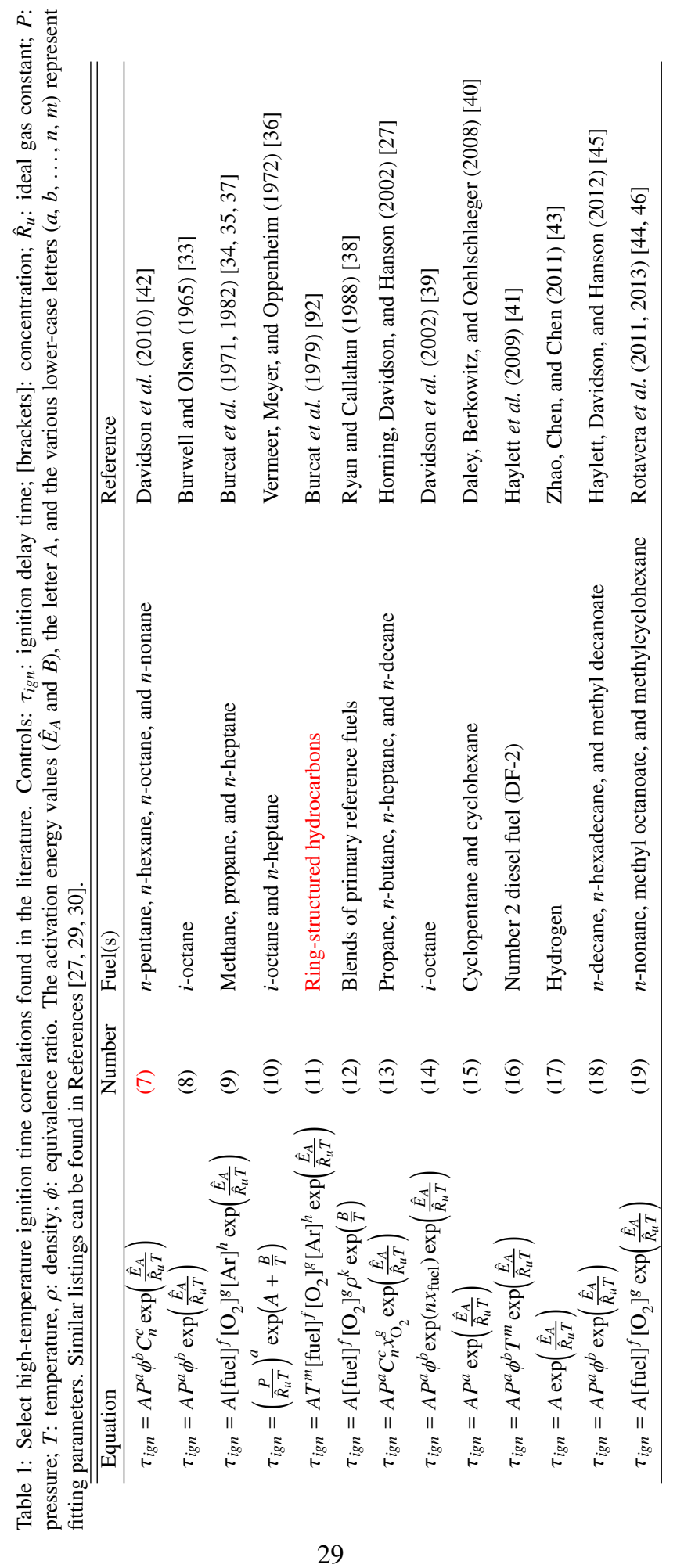


Table 2: Experimental conditions studied in References [50, 51] for MD, MLA, MM, MP, MO, and ML. Column headings: $C_{n}$ : carbon chain length; $U_{d}$ : degree of unsaturation; $T$ : temperature; $P$ : pressure; $\phi$ : equivalence ratio; $x_{\mathrm{O}_{2}}$ : oxygen mole fraction. All mixtures were diluted in argon. The combined data sets of the two studies contain 181 ignition delay time values.

\begin{tabular}{|c|c|c|c|c|c|c|c|c|}
\hline Fuel & Formula & $C_{n}$ & $U_{d}$ & $T[\mathrm{~K}]$ & $P$ [atm] & $\phi$ & $x_{\mathrm{O}_{2}}$ & Ref. \\
\hline MD & $\mathrm{C}_{11} \mathrm{H}_{22} \mathrm{O}_{2}$ & 10 & 0 & 1026-1388 & 7 & 0.5 & $0.01,0.21$ & [51] \\
\hline MLA & $\mathrm{C}_{13} \mathrm{H}_{26} \mathrm{O}_{2}$ & 12 & 0 & 1163-1354 & $3.5,7$ & $0.75,1.25$ & 0.04 & [51] \\
\hline MM & $\mathrm{C}_{15} \mathrm{H}_{30} \mathrm{O}_{2}$ & 14 & 0 & $1162-1357$ & $3.5,7$ & $0.75,1.25$ & 0.04 & [51] \\
\hline MP & $\mathrm{C}_{17} \mathrm{H}_{34} \mathrm{O}_{2}$ & 16 & 0 & $1180-1311$ & $3.5,7$ & $0.375,0.75$ & 0.04 & [51] \\
\hline MO & $\mathrm{C}_{19} \mathrm{H}_{36} \mathrm{O}_{2}$ & 18 & 1 & $1115-1370$ & $3.5,7$ & $0.75,1.25,2$ & 0.04 & [50] \\
\hline ML & $\mathrm{C}_{19} \mathrm{H}_{34} \mathrm{O}_{2}$ & 18 & 2 & $1128-1378$ & $3.5,7$ & $0.75,1.25,2$ & 0.04 & [50] \\
\hline
\end{tabular}


Table 3: Best-fit parameters for Equation 1 based on MLA, MM, MP, MO, and ML ignition delay times at oxygen mole fraction $x_{\mathrm{O}_{2}}=0.04$ (diluted in argon; 166 data points). The \pm numbers are standard error values for the fitting parameters.

\begin{tabular}{lll}
\hline \hline Quantity & Value & Standard Error \\
\hline$A$ & $2.24 \times 10^{-6} \mathrm{~ms}$ & $\pm 0.71 \times 10^{-6} \mathrm{~ms}$ \\
$a$ & -0.41 & \pm 0.04 \\
$b$ & 0.30 & \pm 0.03 \\
$c$ & -0.61 & \pm 0.08 \\
$\hat{E}_{A}$ & $37.1 \mathrm{kcal} / \mathrm{mol}$ & $\pm 0.7 \mathrm{kcal} / \mathrm{mol}$ \\
Parameters & & \\
$T$ range & $1115-1378 \mathrm{~K}$ & \\
$P$ range & $3.2-7.3 \mathrm{~atm}$ & \\
$\phi$ range & $0.27-2.39$ & \\
$C_{n}$ range & $12-18$ & \\
$U_{d}$ range & $0-2$ & \\
$x_{\mathrm{O}_{2}}$ & 0.04 & \\
\hline
\end{tabular}


Table 4: Oxygen mole fraction scaling parameters $g$ for MD, MP, MO, and ML (see Equation 4). The \pm numbers are standard error values for the fitting parameters, and the number of ignition delay time points used to derive each value are also given.

\begin{tabular}{lllll}
\hline \hline Fuel & $\begin{array}{l}x_{\mathrm{O}_{2}} \text { Exp. } \\
(g)\end{array}$ & $\begin{array}{l}\text { Standard } \\
\text { Error }\end{array}$ & $\begin{array}{l}x_{\mathrm{O}_{2}} \\
\text { Range }\end{array}$ & $\begin{array}{l}\text { Number of } \\
\text { Points }\end{array}$ \\
\hline MD & -0.47 & \pm 0.04 & $0.01-0.21$ & 47 \\
MP & -0.42 & \pm 0.03 & $0.04-0.21$ & 38 \\
MO & -0.60 & \pm 0.03 & $0.04-0.21$ & 17 \\
ML & -0.65 & \pm 0.03 & $0.04-0.21$ & 22 \\
\hline
\end{tabular}


Table 5: Comparison of high-temperature ignition delay correlation parameters determined in this study (for MD, MLA, MM, MP, MO, and ML, according to Equations 1 and 4) and parameters from the literature (see Table 1). For uncertainties in the parameters from this study, see Tables 3 and 4 A similar table can be found in Imbert et al. [30].

\begin{tabular}{|c|c|c|c|c|c|c|c|c|}
\hline Fuel(s) & $\begin{array}{l}P \text { Range } \\
{[\mathrm{atm}]}\end{array}$ & $x_{\mathrm{O}_{2}}$ Range & $\begin{array}{l}P \text { Exp. } \\
(a)\end{array}$ & $\begin{array}{l}\phi \text { Exp. } \\
\text { (b) }\end{array}$ & $\begin{array}{l}C_{n} \text { Exp. } \\
(c)\end{array}$ & $\begin{array}{l}x_{\mathrm{O}_{2}} \text { Exp. } \\
(g)\end{array}$ & $\begin{array}{l}\hat{E}_{A} \\
{[\mathrm{kcal} / \mathrm{mol}]}\end{array}$ & Refer \\
\hline MLA, MM, MP, MO, and ML & $3.2-7.3$ & 0.04 & -0.41 & 0.30 & -0.61 & & 37.1 & This $\mathrm{s}$ \\
\hline MD & $6.4-50.5$ & $0.01-0.21$ & & & & -0.47 & & This $s$ \\
\hline MP & $3.2-21$ & $0.04-0.21$ & & & & -0.42 & & This $\mathrm{s}$ \\
\hline MO & $6.5-10.9$ & $0.04-0.21$ & & & & -0.60 & & This \\
\hline ML & $6.3-10.4$ & $0.04-0.21$ & & & & -0.65 & & This s \\
\hline Methyl octanoate $\left(\mathrm{C}_{9} \mathrm{H}_{18} \mathrm{O}_{2}\right)$ & $1-10$ & 0.01 & -0.19 & & & & 48.7 & [46] \\
\hline $\mathrm{MD}$ & 8 & 0.21 & -1.32 & -1.2 & & & 44.3 & 45] \\
\hline MD & $13.7-18.5$ & 0.21 & & -0.51 & & & 29.4 & {$[56$} \\
\hline MD & 7 & 0.21 & & & & & 25.9 & {$[51]$} \\
\hline MD & 7 & 0.01 & & & & & 47.3 & [51] \\
\hline MP & $10-20$ & 0.21 & -0.8 & -0.5 & & & & {$[58$} \\
\hline$n$-alkanes $\mathrm{C}_{3}, \mathrm{C}_{4}, \mathrm{C}_{7}$, and $\mathrm{C}_{10}$ & $1-6$ & $0.02-0.20$ & -0.55 & & -0.50 & -0.63 & 46.55 & [27] \\
\hline$n$-alkanes $\mathrm{C}_{5}, \mathrm{C}_{6}, \mathrm{C}_{8}$, and $\mathrm{C}_{9}$ & 2 & 0.04 & -0.53 & 0.80 & -0.24 & & 44.77 & 42] \\
\hline$n$-nonane $\left(\mathrm{C}_{9} \mathrm{H}_{20}\right)$ & $1-10$ & 0.01 & -0.48 & & & & 51.0 & [46] \\
\hline$n$-hexadecane $\left(\mathrm{C}_{16} \mathrm{H}_{34}\right)$ & $2-5$ & $0.01-0.04$ & -0.73 & 0.82 & & -0.54 & & [45] \\
\hline$i$-octane & $1.2-8.2$ & $0.005-0.06$ & -0.56 & 1.62 & & & 44.78 & [39] \\
\hline DF-2 & $2.3-8$ & 0.21 & -1.03 & -1.02 & & & & [41] \\
\hline
\end{tabular}


Table 6: Best-fit parameters for Equation 1. derived by linear regression from the Herbinet et al. [76], Westbrook et al. [50, 77, 78], and Saggese et al. [88, 90] biodiesel models. The best-fit values for the Herbinet model are based only on MLA, MM, and MP because it does not include unsaturated species (e.g., MO and ML), and those for the Westbrook and Saggese models are based only on MP, MO, and ML because they do not include species smaller than MP (i.e., MM and MLA). Standard error values for the fitting parameters derived in this study can be found in Table 3 Diluent is argon.

\begin{tabular}{|c|c|c|c|c|}
\hline Quantity & This Study & Herbinet et al. (2011) [76] & Westbrook et al. (2011) [50, 77, 78] & Saggese et al. (2013) [88, 90] \\
\hline$A$ & $2.24 \times 10^{-6} \mathrm{~ms}$ & $3.54 \times 10^{-8} \mathrm{~ms}$ & $8.87 \times 10^{-8} \mathrm{~ms}$ & $7.14 \times 10^{-7} \mathrm{~ms}$ \\
\hline$a$ & -0.41 & -0.78 & -0.46 & -0.69 \\
\hline$b$ & 0.30 & 0.74 & 0.22 & 0.039 \\
\hline$c$ & -0.61 & 0.072 & {$[0]$} & {$[0]$} \\
\hline$\hat{E}_{A}$ & $37.1 \mathrm{kcal} / \mathrm{mol}$ & $46.7 \mathrm{kcal} / \mathrm{mol}$ & $40.8 \mathrm{kcal} / \mathrm{mol}$ & $37.3 \mathrm{kcal} / \mathrm{mol}$ \\
\hline \multicolumn{5}{|c|}{ Parameters } \\
\hline$T$ range & $1115-1378 \mathrm{~K}$ & $1115-1378 \mathrm{~K}$ & $1136-1333 \mathrm{~K}$ & $1150-1375$ \\
\hline$P$ range & $3.2-7.3 \mathrm{~atm}$ & $3.5-7 \mathrm{~atm}$ & $3.5-7 \mathrm{~atm}$ & $3.5-7 \mathrm{~atm}$ \\
\hline$\phi$ range & $0.27-2.39$ & $0.375-1.25$ & $0.375-2$ & $0.375-2$ \\
\hline$C_{n}$ range & $12-18$ & $12-16$ & $16-18$ & $16-18$ \\
\hline$U_{d}$ range & $0-2$ & 0 & $0-2$ & $0-2$ \\
\hline$x_{\mathrm{O}_{2}}$ & 0.04 & 0.04 & 0.04 & 0.04 \\
\hline
\end{tabular}

